\title{
"Not Another Multicultural Education Workshop" (sigh): Why Teachers Feel Intimidated by More and More Workshops in Multicultural Education.
}

\author{
Beate Baltes, \\ National University
}

Many educators consider themselves sensitive to diversity issues in one way or another. However, it is not uncommon for some teachers to feel intimidated by more and more staff development programs in multicultural education that they are urged or compelled to attend. This article suggests ways in which multicultural education workshops could be made meaningful for them.

Nowadays, teacher education is facing a lot of criticism for the shortcomings of school teachers. One area of criticism is multicultural education. Many critics, including some teachers, regard multicultural education as a tool for some people with political agendas. It is therefore not surprising for some teachers to feel intimidated by the number of workshops in multicultural education that they are required to attend.ii

Educators in the $21^{\text {st }}$ century are aware of demographic changes, technological developments, global interdependency, as well as the increase in violence and ethnic hostility. It is not surprising that many educators have developed a certain sensitivity to the diversity in this increasingly culturally pluralistic nation. Why, then, do they need to participate in some more multicultural education workshops? Indeed, research shows that many multicultural education efforts are ineffective. 
However, the results do vary, as demonstrated in the following brief summary of three studies of staff development approaches.

George L. Redman, for example, describes the effects of a ten week human relations training program that was based on the following goals: (a) to understand the contributions and life styles of the various racial, cultural and economic groups in society; (b) to recognize and deal with dehumanizing biases, discrimination and prejudices; (c) to create learning environments which contribute to the self-esteem of all persons and to positive interpersonal relationships; (d) to respect human diversity and personal rights.iii In his first human relations training program during the winter quarter of 1974-75 eighty-eight school personnel (non-life certified teachers, counselors, administrators, and other school personnel at the preschool, elementary, secondary, and college level) participated. In a second human relations training program during the spring quarter of 1975-76 ninety school personnel participated. The study showed that a positive change in empathetic reaction to minority people can be achieved and that these positive changes were still apparent two and one-half months after the completion of the program.

Several years later, Valora Washington conducted a five day workshop in an attempt to change multicultural education attitudes and multicultural classroom behaviors of forty-nine elementary school teachers in rural North Carolina. The results of a pre-/post-test measure showed that the training's impact was negligible. The attitudinal and behavioral ratings remained either constant or even declined slightly. iiii

Again, several years later, Christine Sleeter and Susan Gould conducted a staff development project for multicultural education with thirty teachers from eighteen different schools. The project began with nine days per year built into the teachers' regular teaching schedule and was expanded by five more days in a second year. Sleeter concluded that the changes brought about by staff development structured around an individual development model are modest and uneven. She concluded that as long as the context and demands of teaching 


\section{Ethnic Studies Review Volume 21}

remain structured as they are, teachers will tend to do little with multicultural education unless they happen to be people who "buck the system".v In summary, the research results on the effectiveness of multicultural education efforts not only vary but also indicate that workshops do not accomplish very much which leads to even more teacher resistance to participation in multicultural education efforts. This article suggests ways to overcome at least some of these negative attitudes and alleviate the educators' frustrations, which are certainly not conducive to the success of multicultural education.

\section{The Problem with the Concept}

The term multicultural education has many different meanings and thus may convey different things to different people. Philosophies range from helping students assimilate into the cultural mainstream to encouraging students to take activist positions and challenge social inequalities. This variation frequently results in workshops that are weakly conceptualized and, worst of all, misinterpreted.

On the one hand trainers in multicultural education workshops often forget that educators already have an idea of what goals multicultural education should have and that they are already applying certain strategies in their classrooms. Nevertheless, workshops are often presented to all teachers in the same way and thus do not address the individual teacher's philosophy or level of awareness of multicultural education issues. On the other hand participants often forget that a trainer might have a different philosophy that he/she is trying to promote. Usually, the issue of multicultural education is discussed during workshops without considering these backgrounds which leads to close-mindedness among participants and misunderstandings rather than meaningful communication.

\section{Some Recommended Solutions}

In order to change the sometimes negative attitudes of educators who are urged to attend multicultural education workshops, a trainer could consider the following: 
I Presentation of an established theoretical framework of multicultural education that demonstrates the range of philosophies of multicultural ed cation;

II Determination of participants' present philosophies of multicultural education;

III Statement about the trainer's philosophy of multicultual education which will be promoted during the workshop;

IV Realization of personal life experiences and/or schoolrelated factors that might have influenced the develop ment of educators' multicultural education philosophies.

After this introduction to a multicultural education workshop the communication between the trainer and the participants would be based on clear ideas of each other's philosophies, thus opening up opportunities for a meaningful discussion.

\section{Implementation of the Solutions}

The four steps of the solution could be implemented in the following way:

\section{Presentation of an Established Theoretical Framework of Multicultural Education}

I personally consider the theoretical framework proposed by Christine Sleeter and Carl Grant to be the most comprehensive at this time. vi Sleeter and Grant reviewed the existing literature which claims multicultural education as its subject and developed a taxonomy that illustrates five distinct philosophies of multicultural education:

Teaching the Culturally Different (CD): This approach simply recognizes distinct personalities. Teachers assist students in acquiring the knowledge, skills, and attitudes that allow them to participate successfully in, as well as to compete with, the public culture of the dominant group. Even if students are encouraged to maintain their own cultural identity, teachers see the goal of multicultural education as providing transitional bridges for their students of color to assimilate into the cultural mainstream and into the existing social structure.

Human Relations (HR): This approach focuses on cooperation and communication between people of different backgrounds. 


\section{Ethnic Studies Review Volume 21}

This concept is aimed mainly at the affective level - at the attitudes and feelings people have about themselves and others. It attempts to foster good relationships among students of diverse heritage to replace tension and hostility with acceptance and care.

Single Group Studies (SS): This approach fosters cultural pluralism by recognizing all cultural groups as equal and by honoring the intrinsic worth of all human beings. Respondents to this approach strive to develop acceptance, appreciation, and empathy for a rich cultural and linguistic diversity. This approach implies a transmission of the traditions of all cultures equally and respectfully so that students not only cherish their own ways of life but also respect those of others.

Multicultural Education (MC): This approach promotes cultural pluralism and social equality by appreciating, protecting, and enhancing diverse cultures. Gollnick summarized the five major goals of this approach as (a) promoting strength and value of cultural diversity; (b) developing a sense for human rights and respect for cultural diversity; (c) changing discrimination in society; (d) developing acceptance for social justice and equal opportunity for all people; and (e) developing a sense for equal distribution of power among all individuals and groups.vii

Multicultural Education and Social Reconstruction (SR): This approach goes a step beyond the preceding approach by also requiring multicultural education to prepare students to question the status quo and to challenge the existing social structural inequalities. It invites students to become skilled workers and thinking citizens who are also agents for change and social critics. This definition implies a common responsibility to work actively towards social structural equality and equal opportunity in schools.

\section{Determination of Participants' Present Philosophies of Multicultural Education}

At the beginning of a workshop in multicultural education, the trainer should determine the participants' present philosophies of multicultural education. This could be done through discussion but might be more time efficient when conducted in the form of a questionnaire, such as the "Assessment of 
Multicultural Education Philosophy" (see Appendix). This instrument identifies teachers' tendencies towards one of the five approaches determined by Christine Sleeter and Carl Grant.

To give the workshop participants at least some indication of how their personal philosophy compares to other teachers' philosophies, the trainer could give the participants the results of a study that used the "Assessment of Multicultural Education Philosophy" instrument. viii The study was conducted within the San Diego Unified School District with 509 teachers (a fourth of the teacher population) of junior and senior high schools. Study results indicated that HR was the most common approach with 35.2 percent of the educators selecting it. The second most common approach was SS with 23.6 percent followed by MC with 17.5 percent. SR and $C D$ turned out to be the least common approaches with 13.7 percent and 10.0 percent respectively.

Figure 1. Frequency of the Approaches to Multicultural Education in the San Diego Unified School District.

III. Statement about the Trainer's Philosophy of Multicultural Education

Now that participants are aware of their own philoso-

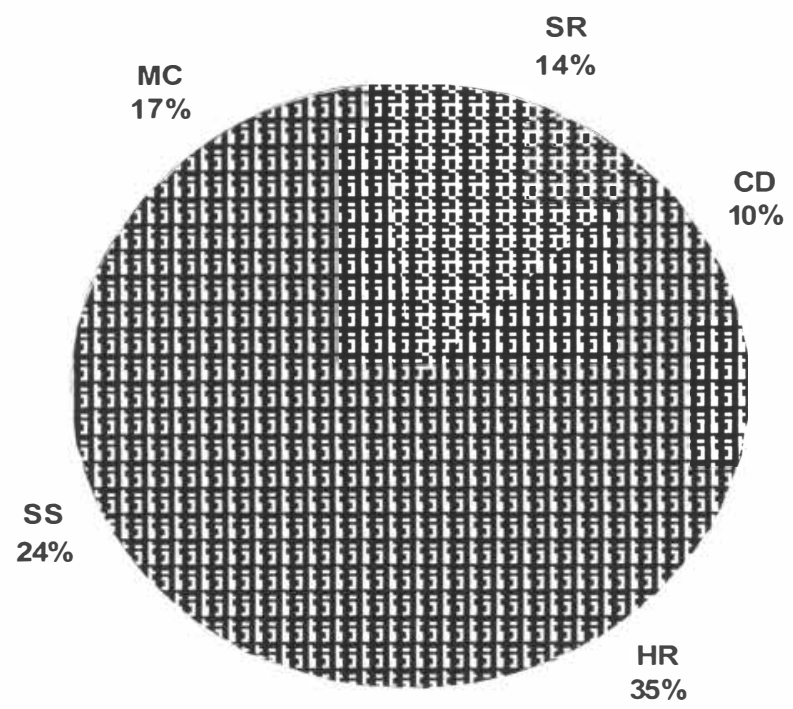


phies, the trainer needs to expain his/her personal philosophy of multicultural education. Many teachers' initial attitude towards attending another multicultural education workshop is that it is a waste of time since they implement multicultural education in one way or another in their classrooms already. Some even feel intimidated that they are urged to attend another one.

A trainer needs to clearly state which of philosophies of multicultural education identified by Sleeter and Grant will be promoted during this particular workshop. Through examples of how this approach would be implemented in the classroom, the potential benefits to school children become clear. Further discussion of the appropriateness of the trainer's goal can build the underlying rationale for this workshop and, consequently, the workshop becomes much more meaningful for its participants. For example, if teachers formerly brought artifacts or foods into the classroom, particularly on ethnic holidays, then these teachers will understand why a trainer proposing the SR approach might encourage them to rethink and reconsider the classroom implications of such 'ethnic cuisine days.'

\section{Realization of Personal Life Experiences and/or School- related Factors that Might Have Influenced the Development of Philosophies of Multicultural Education} Even if the participants learn about different philosophies of multicultural education, and even if they would like to move their own philosophies towards, for example, a more activist approach to multicultural education, educators still do not know which factors influence the development of their personal philosophies. As mentioned above, workshops often fail to alter multicultural education approaches. Consequently, the trainer in a workshop should indicate to the participants which personal life experiences and school-related factors are associated with the development of a multicultural education philosophy. The above-mentioned research study revealed four factors.

1. School Community Support for Multicultural Education: Schools need to be aware of the support a teacher needs from parents, principals, and fellow teachers. A principal's support alone is not sufficient in the teacher's multicultural education efforts. A teacher also needs to encourage parents and fellow 
teachers to be supportive of multicultural education efforts. This is probably easier said than done. Consequently, workshops in multicultural education should address how educators can effectively get this much-needed support by, for example, effectively communicating the importance of multicultural education to the community and its benefits for the community.

2. Social Activism: To engage in social activism is a decision every individual needs to make by himself or herself. Workshops could provide information on social activist movements and encourage faculty and administration to be proactive. The workshop could include participation in volunteer activities throughout the community which might lead to an extension of this volunteer work in teachers' own time. Last but not least, workshops offer a great opportunity to recognize and honor a teacher's engagement in social activism.

3. Classroom Work: This factor includes constraints due to the large number of students in classrooms, the time teachers can spend with these students, and the strict requirements of the curriculum. Since these constraints are often state-mandated, the school administration rarely has opportunities to limit them. Although the time and the number of students teachers have is regulated, workshops could encourage creativity and express appreciation for extra efforts made by the teachers. Furthermore, during parts of a workshop the facilitator should teach participants how to either rewrite their own lesson plans from a multicultural perspective and/or how to use existing resources within the school or outside resources like the internet. When planning a workshop in multicultural education there should be a set aside time for teachers to redesign lessons they are actually using in their classrooms.

4. Exposure to Diversity. It is hard for a school to regulate its teachers' exposure to diversity. Educators have had their experiences in schools, colleges, and in the neighborhoods they lived in as children. These experiences have long lasting effects that are often difficult to alter. Moreover, it cannot be expected that educators would move into more diverse neighborhoods in order to foster their own development in multicultural education. However, in practical terms, networking among educators from different ethnic backgrounds could be encouraged to volunteer to teach in a community different from 


\section{Ethnic Studies Review Volume 21}

their own.

\section{Summary and Conclusion}

Multicultural education means different things to different people. Probably the only common meaning is that multicultural education is supposed to benefit people of color. If multicultural education aims at respecting diversity, then it seems more than natural that multicultural education workshops should be conducted under the premise of respecting the diverse philosophies of the participants. This would make these workshops more attractive to educators and, consequently, may be more successful.

Future research should focus on determining the following:

(a) which philosophy of multicultural education has the highest impact on altering students' respect for diversity. Currently, trainers tend to promote a certain philosophy of multicultural education based on their personal beliefs or based on the school's philosophy;

(b) which theoretical framework would be best used as the premise for a workshop. Certain workshops, for example, those that relate to mainly practical applications in the classroom, might benefit more from the framework developed by James Banks that determines different approaches to multicultural curriculum reform. ix

(c) how the participants' attitudes changed during a workshop in multicultural education. Currently, the success of workshops in multicultural education is measured by the perceptions of participants themselves, and the impact of this training over time is rarely assessed at all.

\section{NOTES}

i A version of this article was presented at the annual conference of the National Association of Ethnic Studies in 1996.

ii M. Williams, "Multicultural/Pluralistic Education: Public Education in America 'the way it's 'spoze to be';" The Clearinghouse 56(1982): 131-5. 
iii George L. Redman, "Study of the Relationship of Teacher Empathy for Minority Persons and Inservice Human Relations Training," Journal of Educational Research 70(1977): 205-10.

iv Valora Washington, "Impact of Antiracism/Multicultural Education Training on Elementary Teachers' Attitudes and Classroom Behavior," The Elementary School Journal 81(1981): 186-92.

$\checkmark$ Christine E. Sleeter, Keepers of the American Dream: A Study of Staff Development and Multicultural Education (Bristol, PA: Falmer, 1992).

vi Christine E. Sleeter and Carl A. Grant, "An Analysis of Multicultural Education in the United States," Harvard Educational Review, 57(1987): 421-44.

vii Donna M. Gollnick, "Multicultural Education," Viewpoints in Teaching and Learning 56(1980): 1-17.

viii Beate Baltes, "Personal Life Experiences and School-related Factors Associated with Teachers' Approaches to Multicultural Education" (Ed.D. diss., United States International University, 1996).

ix James Banks, "Approaches to Multicultural Curriculum Reform," in Multicultural Education: Issues and Perspectives, ed. James A. Banks and Cherry Banks (Boston: Allyn and Bacon, 1993), 195-214.

Beate Baltes Ed.D. is an Assistant Professor in the Department of Teacher Education at National University in Los Angeles, California

\section{Appendix}

\section{Assessment of Multicultural Education Philosophy?}

The following paragraphs are descriptions of five distinct approaches to multicultural education. Please circle the ONE number 1, 2, 3, 4, or 5 that best represents your thinking. Read each statement carefully!

1. This approach assists students in acquiring the knowl- 


\section{Ethnic Studies Review Volume 21}

edge, skills, and attitudes allowing them to participate successfully in the public culture of the dominant group. Even if students are encouraged to maintain their own cultural identity, teachers see the goal of multicultural education as providing transitional bridges for their students of color to raise their achievement, such as relating the curriculum to the experiences and interests of students of color.

2. This approach focuses on cooperation and communication between people of different backgrounds. It attempts to foster good relationships among students of diverse heritage so that they get along with each other and that they are able to work together. Acceptance and care replaces tension and hostility. Misunderstandings are counteracted through lessons about stereotyping as well as individual differences and similarities.

3. This approach fosters cultural pluralism in recognizing all cultural groups as equal and in honoring the intrinsic worth of all human beings. It implies a transmission of the traditions of all cultures equally and respectfully so that students not only cherish their own ways of life but also respect those of others. To counterbalance the prevailing study of the mainstream culture, this approach provides information on the heritage and contributions of distinct ethnic groups.

4. This approach promotes cultural pluralism and social equality by appreciating, protecting, and enhancing diverse cultures. It promotes strength and value of cultural diversity, develops a sense for human rights and respect for cultural diversity, changes discrimination in society, develops acceptance for social justice and equal opportunity for all people, and develops a sense for equal distribution of power among all individuals and groups.

5. This approach promotes cultural pluralism and social equality through encouraging a common responsibility to work actively towards social structural equality and equal opportunity in schools. Teachers prepare students to 
develop the knowledge, skills, and values needed to question the status quo, to challenge the existing structural inequalities, and to reconstruct society to better serve the interests of all groups.

Thank you for your interest. All information will be kept confidential. 